\section{Factors influencing psychotropic prescription by non-psychiatrist physicians in a nursing home for the elderly in Brazil}

\author{
Universidade Estadual Paulista, Rio Claro, São Paulo, Brazil
}

- Florindo Stella

- Dorgival Caetano

- Jaime Lisandro Pacheco

- Elisandra Villela Gasparetto Sé

- Acioly Luiz Tavares Lacerda
INTRODUCTION

As people grow older, disease prevalences rise and medicines for concomitant systemic and central nervous system (CNS) illnesses may be required. The drug-to-drug interaction risk may be further increased by the misuse of psychotropics in nursing homes. ${ }^{1}$ Additionally, age-related biological changes involving both pharmacokinetic and pharmacodynamic parameters are present in the elderly. Decreases in both hepatic metabolism and renal excretion favor the occurrence of drug interaction, especially in the case of substances with prolonged elimination half-life. ${ }^{2}$ In this context, the evaluation of prescribing patterns for psychotropics in nursing homes appears to be of particular interest.

Previous studies have suggested that prescription of psychotropics in nursing homes is importantly influenced by the subject's demographic characteristics, and more so than by diagnostic features. ${ }^{3,4}$ Although psychotropics are one of the classes of medications most prescribed in nursing homes for the elderly, studies examining their prescribing patterns are limited in both number and scope. These studies have reported a wide range of prevalence of psychotropic prescription (10-60\%) and have mainly focused on the classes of psychotropics and prevalence of psychiatric morbidity among residents. ${ }^{5}$ Moreover, although the presence of medical illness seems to negatively affect the identification of psychiatric morbidity by general practitioners, ${ }^{6}$ there is to our knowledge no systematic study examining how the prescription of non-psychotropic drugs may influence the non-psychiatrist physician's decision-making process for prescribing psychotropics for the elderly in developing countries.

口BJECTIVE

The present study was undertaken to investigate factors associated with general psychotropic use in a nursing home in Brazil.
METHODS

\section{SUBJECT:}

Using a retrospective observational study design, we examined 108 elderly individuals living in a nursing home in the city of Rio Claro, São Paulo, Brazil, that caters for poor elderly individuals living in the region. Of these residents, 65 (60.2\%) to whom some kind of drug had been prescribed on a regular basis made up our sample. Thirty-eight residents (58.5\%) were on drugs for cardiovascular diseases. To examine the relationship between concomitant use of psychotropics and cardiovascular disease, the subjects were divided into four subgroups: A) 22 with cardiovascular diseases alone; B) 16 with cardiovascular diseases and other clinical diseases; C) 21 with clinical diseases but no cardiovascular problems; D) six with no clinical or cardiovascular disease. The subjects' identities remained undisclosed throughout the stages of the study and all the recommendations of the Helsinki declaration and the local ethical committee were met.

\section{DATA CRLLECTED}

Information on prescriptions, and also clinical and demographic data, was retrieved from the medical records for 2004. With the aim of obtaining a more homogeneous sample, the subjects who were receiving drugs on an "as needed" basis (i.e., without defined posology) were excluded. In accordance with the type of drug prescribed, the subjects were divided into three groups: 1) those taking only psychotropics; 2) those taking only non-psychotropic drugs; 3) those taking psychotropic and nonpsychotropic drugs simultaneously.

\section{BTATIBTICAL ANALYBIB}

Statistical analyses were carried out using SPSS for Windows, version 11 (Chicago, 2002) and a two-tailed statistical significance

\section{ABSTRACT}

CONTEXT AND OBJECTIVE: Although psychotropics are one of the classes of medications most prescribed in nursing homes for the elderly, studies examining prescribing patterns are limited in both number and scope. The present study was undertaken to investigate factors associated with general psychotropic use in a nursing home in Brazil.

DESIGN AND SETTING: Retrospective observational study at the Nursing Home for the Elderly, Institute of Biosciences, Universidade Estadual Paulista.

METHODS: Information on prescriptions was retrieved from the medical records of 108 elderly residents in a nursing home. Sixty-five of these patients, with mean age 74.5 years ( \pm standard deviation 9.4 years), who were taking medications on a regular basis, comprised the sample. The effects of demographic and clinical variables on the psychotropic prescription pattern were examined.

RESULTS: Females were more likely to receive psychotropics ( $p=0.038)$. Individuals on medicines for cardiovascular diseases received psychotropics less frequently $(p=0.001)$. The number of prescribed psychotropics correlated negatively with both age $(p=0.009)$ and number of non-psychotropic drugs ( $p=0.009$ ).

CONCLUSIONS: Although preliminary, the present results indicated that cardiovascular disease was the clinical variable that most influenced psychotropic prescription. Physicians' overconcern regarding drug interactions might at least partially explain this result. Further investigations involving larger sample sizes from different regions are warranted to confirm these findings.

KEY WORDS: Aging. Homes for the aged. Drug prescriptions. Heart diseases. Psychopharmacology. 
level was set at 0.05 . Analysis of covariance (ANCOVA) was conducted, with the number of non-psychotropic drugs as the dependent measurements, psychotropic use entered as the independent variable, and age as a covariable. The same model was utilized with the chi-squared test to assess the gender effect on psychotropic prescription. Spearman's rho correlation coefficients (r) were used to investigate relationships between demographic variables (age) and clinical variables (numbers of psychotropic and non-psychotropic drugs), since their distribution was non-normal (Shapiro-Wilks test).

RESULTS

The subjects' ages ranged from 58 to 97 years (mean \pm standard deviation $(\mathrm{SD})=$ $74.31 \pm 9.42)$. The mean number of drugs taken daily was 3.8 .

Although psychotropics were frequently prescribed on a regular basis, neither the diagnoses nor the evaluations by psychiatrists were registered in the medical records. Fortyone subjects (63.1\%) were on psychotropics alone, or in combination with non-psychotropic drugs. Eight subjects (12.3\%) were on psychotropics exclusively (group 1), with a mean of 2.8 psychotropics taken daily. Among the patients taking psychotropics, 23 subjects were on benzodiazepines, 19 on antipsychotic drugs and 8 on antidepressants, and 16 were taking drugs in other psychotropic classes such as anticonvulsants, anticholinergics and cholinesterase inhibitors. Twenty-four subjects (36.9\%) were exclusively on non-psychotropic drugs (mean: 3.7 drugs) (group 2). Thirtythree subjects $(50.8 \%)$ were concomitantly taking psychotropic and non-psychotropic drugs (mean: 4.2 drugs). Table 1 summarizes the drug prescriptions.

The subjects on psychotropics $(\mathrm{n}=35)$ received more non-psychotropic drugs than did those not taking psychotropics $(3.4 \pm 1.54$ versus $2.09 \pm 1.68 ; \mathrm{F}_{162}(\mathrm{~F}$ statistic $)=9.98$, $\mathrm{p}=0.002$ ). Although the subjects not receiving psychotropics were older, this difference did not reach significance $(76.43 \pm 9.68$ versus $72.49 \pm$

Table 1. Daily medications prescribed for 65 residents of a nursing home in Brazil

\begin{tabular}{lccc}
\hline Groups & $\mathbf{n}$ & $\%$ & $\begin{array}{c}\text { Number of drugs } \\
\text { Mean (SD) }\end{array}$ \\
\hline Psychotropics & 8 & 12.3 & $2.8(2.5)$ \\
Non-psychotropics & 24 & 36.9 & $3.7(3.0)$ \\
Psychotropics plus non-psychotropics & 33 & 50.8 & $4.2(4.0)$ \\
\hline Total & $\mathbf{6 5}$ & $\mathbf{1 0 0 \%}$ & $\mathbf{3 . 8}$ \\
\hline
\end{tabular}

8.94 years, $t$ (Student's $\mathrm{t}$ test $)=1.52, \mathrm{df}($ degrees of freedom) $=63, p=0.093)$. Female subjects $(\mathrm{n}=36)$ were prescribed psychotropics more often $\left(\chi^{2}=4.298, \mathrm{df}=1, \mathrm{p}=0.038\right)$. However, females and males did not differ in terms of quantity of psychotropics $(1.0 \pm 1.09$ versus $\left.1.29 \pm 1.15 ; \mathrm{F}_{1.62}=2.12, \mathrm{p}=0.15\right)$.

Group A (individuals with cardiovascular diseases alone) took significantly less psychotropics in comparison with the other groups $(\mathrm{B}=$ subjects with cardiovascular diseases and other clinical diseases; $\mathrm{C}=$ subjects with clinical diseases but no cardiovascular problems): ANCOVA, age as a covariable, $\mathrm{F}_{2.61}=7.59, \mathrm{p}=0,001$. The subjects in groups $\mathrm{A}$ and $\mathrm{B}$ did not display a significant difference in relation to the number of psychotropics prescribed $(0.73 \pm 0.93$ versus $0.69 \pm 0.79$; $\mathrm{t}=1.38, \mathrm{df}=36, \mathrm{p}=0.89$ ).

There were negative correlations between both the number of prescribed psychotropics and age $(\mathrm{r}($ Spearman's $r$ ro $)=-0.321, \mathrm{p}=0.009)$ on the one hand and the number of prescriptions for psychotropic and non-psychotropic drugs $(r=-0.58, p<0.001)$, on the other. Groups B and C did not differ with regard to age $(73.5 \pm 9.8$ versus $72.22 \pm 8.16$ years, $\mathrm{t}=0.459, \mathrm{df}=41, \mathrm{p}=0.648)$. However, there was a trend for subjects in group $\mathrm{A}$ to be older than those in group C $(77.45 \pm$ 10.12 versus $72.22 \pm 8.16$ years, $t=2.003$, $\mathrm{df}=47, \mathrm{p}=0.051)$.

DISCUSSION

In the present study, nursing home resiprescriptions for psychotropics and a greater number of prescriptions for non-psychotropics, as compared with those with other medical diseases. The number of psychotropics prescribed correlated negatively with both age and number of prescriptions for nonpsychotropic drugs. Females were more likely to have psychotropic prescriptions than their male counterparts.

Approximately $38 \%$ of the residents were on psychotropics, with a mean of 2.8 drugs taken daily. This is in agreement with studies ${ }^{3,5}$ dents with cardiovascular diseases had fewer examining the prevalence of the use of psychotropics among nursing home residents. These studies have reported rates ranging from $27 \%$ to $60 \%$, which are higher than the rates of 9.3 to $30.6 \%$ found in community studies. ${ }^{7-9}$ Also, other previous studies ${ }^{10,11}$ have reported average numbers of psychotropic drugs prescribed that were similar to what was found in the present study.

Cardiovascular disease is an important risk factor for vascular dementia. ${ }^{12}$ Whether alone or concomitant with other diseases, cardiovascular disease was associated with a smaller number of psychotropics prescribed and seemed to be the clinical condition that most influenced the physician's decision in prescribing psychotropics. This may be partly explained by the fear of pharmacological interactions and lack of familiarity with drugs not usually prescribed by general practitioners. In fact, different psychotropic drugs have been associated with potentially serious cardiovascular side effects, for example QTc interval prolongation on eletrocardiogram. ${ }^{13}$ Alternatively, the issue of underdiagnosis of psychiatric disorders by non-psychiatrists may be more evident among patients with cardiovascular diseases, since these conditions may present neurovegetative symptoms that mimic psychiatric symptomatology (such as loss of energy and appetite, chest pain, increased heart rate, dizziness, paresthesia, memory deficits and insomnia)..$^{14}$

Prescribing decisions in nursing homes have raised concerns since evidence supporting them is generally absent. ${ }^{15}$ In the present study, there was a significant negative correlation between the number of prescribed psychotropics and age, which is in line with some previous studies, ${ }^{5}$ but not all. ${ }^{16,17}$ This finding appears to be counterintuitive, since some authors have reported a higher prevalence of mental disorders in the elderly. ${ }^{5}$ This might be explained by the fact that mental disorders are often underdiagnosed and, consequently, undertreated among older people. ${ }^{18}$ Alternatively, overconcern regarding the use of psychotropics among older residents and possible interactions involving psychotropics could at least in part account for this finding. The negative correlation between the numbers of psychotropic and non-psychotropic drugs observed in the present study supports the latter hypothesis.

More women were prescribed psychotropics than men, which is in agreement with some previous studies. ${ }^{19,20}$ but not all. ${ }^{21}$ This may be due to a variety of reasons. Firstly, except for some specific diagnoses, females 
are more likely to have psychotropics prescribed. ${ }^{19,22}$ Secondly, caregivers' attitudes towards behavioral disorders and the physician's ability to diagnose and treat psychiatric disorders may also be biased according to gender. ${ }^{23}$ Finally, gender differences in coping with and expressing psychological suffering might at least partially account for this finding. ${ }^{24,25}$

The present findings should be interpreted with caution since several limitations were present. Firstly, it was an uncontrolled retrospective study conducted in one institution in a city in the interior of Brazil, where access to continuing medical education is limited. Secondly, since only a few individuals had diseases other than cardiovascular disease (such as cerebrovascular diseases, Parkinson's disease, dementia, lung diseases or bone-joint diseases), these conditions were classified together as "other diseases", which thus produced a very heterogeneous group. Finally, the sample size was limited. This latter observation is especially valid with regard to the analyses involving subgroups.

CONCLUSIONS

To our knowledge, this is the first study evaluating the prescription of psychotropics by non-psychiatrist physicians in a nursing home for the elderly in Brazil. Although preliminary, the present results indicate that females were more likely to have psychotropics prescribed, and that age was negatively associated with the number of psychotropics prescribed. Moreover, the presence of cardiovascular disease negatively influenced the prescription of psychotropic medications. General practitioners' overconcern regarding drug interactions when prescribing psychotropics might at least in part explain this finding. Further investigations involving nursing homes from different regions of Brazil are warranted, to explore the reasons for these associations and to test whether the present results can be generalized.
1. Snowdon J, Vaughan R, Miller R, Burgess EE, Tremlett P. Psychotropic drug use in Sydney nursing homes. Med J Aust. 1995;163(2):70-2.

2. Katona CL. Psychotropics and drug interactions in the elderly patient. Int J Geriatr Psychiatry. 2001;16(Suppl 1):S86-90.

3. Buck JA. Psychotropic drug practice in nursing homes. J Am Geriatr Soc. 1988;36(5):409-18.

4. Ruby CM, Kennedy DH. Psychopharmacologic medication use in nursing-home care: Indicators for surveyor assessment of the performance of drug-regimen reviews, recommendations for monitoring, and nonpharmacologic alternatives. Clin Family Practice. 2001;3:577-98.

5. Sorensen L, Foldspang A, Gulmann NC, Munk-Jorgensen P. Determinants for the use of psychotropics among nursing home residents. Int J Geriatr Psychiatry. 2001;16(2):147-54.

6. Robinson MJ, Levenson JL. The use of psychotropics in the medically ill. Curr Psychiatry Rep. 2000;2(3):247-55.

7. Mort JR, Aparasu RR. Prescribing of psychotropics in the elderly: why is it so often inappropriate? CNS Drugs. 2002;16(2):99-109.

8. Dealberto MJ, Seeman T, McAvay GJ, Berkman L. Factors related to current and subsequent psychotropic drug use in an elderly cohort. J Clin Epidemiol. 1997;50(3):357-64.

9. Fichter MM, Witzke W, Leibl K, Hippius H. Psychotropic drug use in a representative community sample: the Upper Bavarian study. Acta Psychiatr Scand. 1989;80(1):68-77.

10. Nirodi P, Mitchell AJ. The quality of psychotropic drug prescribing in patients in psychiatric units for the elderly. Aging Ment Health. 2002;6(2):191-6.
11. Ancill RJ, Embury GD, MacEwan GW, Kennedy JS. The use and misuse of psychotropic prescribing for elderly psychiatric patients. Can J Psychiatry. 1988;33(7):585-9.

12. Smid J, Nitrini R, Bahia VS, Caramelli P. Caracterizaçăo clínica da demência vascular: avaliaçäo retrospectiva de uma amostra de pacientes ambulatoriais. [Clinical characterization of vascular dementia: retrospective evaluation of an outpatient sample]. Arq Neuropsiquiatr. 2001;59(2B):390-3.

13. Reilly JG, Ayis SA, Ferrier IN, Jones SJ, Thomas SH. QTc-interval abnormalities and psychotropic drug therapy in psychiatric patients. Lancet. 2000;355(9209):1048-52.

14. Hansen S. Mental health issues associated with cardiovascular disease in women. Psychiatr Clin North Am. 2003; 26(3):693-712

15. Ryan JM, Kidder SW, Daiello LA, Tariot PN. Psychopharmacologic interventions in nursing homes: what do we know and where should we go? Psychiatr Serv. 2002;53(11):1407-13.

16. Linden M, Lecrubier Y, Bellantuono C, Benkert O, Kisely S, Simon G. The prescribing of psychotropic drugs by primary care physicians: an international collaborative study. J Clin Psychopharmacol. 1999;19(2):132-40.

17. Linjakumpu T, Hartikainen S, Klaukka T, Koponen H, Kivela SL, Isoaho R. Psychotropics among the home-dwelling elderly increasing trends. Int J Geriatr Psychiatry. 2002;17(9):874-83.

18. Aparasu RR, Mort JR, Brandt H. Psychotropic prescription use by community-dwelling elderly in the United States. J Am Geriatr Soc. 2003;51(5):671-7.

19. Hohmann AA. Gender bias in psychotropic drug prescribing in primary care. Med Care. 1989;27(5):478-90.
20. Gleason PP, Schulz R, Smith NL, et al. Correlates and prevalence of benzodiazepine use in community-dwelling elderly. J Gen Intern Med. 1998;13(4):243-50.

21. Holmquist IB, Svensson B, Hoglund P. Psychotropic drugs in nursing- and old-age homes: relationships between needs of care and mental health status. Eur J Clin Pharmacol. 2003;59(89):669-76.

22. Robins LN, Helzer JE, Weissman MM, et al. Lifetime prevalence of specific psychiatric disorders in three sites. Arch Gen Psychiatry. 1984;41(10):949-58.

23. van der Waals FW, Mohrs J, Foets M. Sex differences among recipients of benzodiazepines in Dutch general practice. BMJ. 1993;307(6900):363-6.

24. Mellinger GD, Balter MB, Uhlenhuth EH. Prevalence and correlates of the long-term regular use of anxiolytics. JAMA. 1984;251(3):375-9.

25. Verbrugge LM. Gender and health: an update on hypotheses and evidence. J Health Soc Behav. 1985;26(3):156-82.

Sources of funding: Not declared.

Conflicts of interest: None.

Date of first submission: March 17, 2005

Last received: August 11, 2006

Accepted: August 14, 2006 


\section{AUTHOR INFLRMATION}

Florindo Stella, MD, PhD. Professor, Institute of Biosciences, Universidade Estadual Paulista; Department of Medical Psychology and Psychiatry, Faculdade de Ciências Médicas da Universidade Estadual de Campinas (Unicamp), Campinas, Brazil.

Dorgival Caetano, MD, PhD. Professor, Department of Medical Psychology and Psychiatry, Faculdade de Ciências Médicas da Universidade Estadual de Campinas (Unicamp), Campinas, Brazil.

Jaime Lisandro Pacheco, PhD. Professor, Deparment of Medical Psychology and Psychiatry, Faculdade de Ciências Médicas da Universidade Estadual de Campinas (Unicamp), Campinas, Brazil.

Elisandra Villela Gasparetto Sé, MSc. Researcher, Department of Medical Psychology and Psychiatry, Faculdade de Ciências Médicas da Universidade Estadual de Campinas (Unicamp), Campinas, Brazil.

Acioly Luiz Tavares Lacerda, MD, PhD. Professor, Interdisciplinary Laboratory of Neuroimaging and Cognition, Department of Psychiatry, Universidade Federal de São Paulo (Unifesp), São Paulo, Brazil. Director, Instituto SINAPSE, Campinas, Brazil.

\section{Address for correspondence:}

Florindo Stella

Universidade Estadual Paulista (Unesp)

Instituto de Biociências/Psicologia

Caixa Postal 199

Rio Claro (SP) - Brasil - CEP 13506-900

Tel. (+55 19) 3526-4246 - Fax (+55 19) 3526-4246

E-mail: fstella@rc.unesp.br

Copyright @ 2006, Associação Paulista de Medicina
RESUMD

Fatores que influenciam a prescrição de psicofármacos por médicos não-psiquiatras em um abrigo de idosos no Brasil

CONTEXTO E OBJETIVO: Embora os psicotrópicos sejam uma das classes de medicações mais prescritas em abrigos para idosos, os estudos avaliando o seu padrão de prescrição são limitados em número e escopo. Este estudo visou investigar os fatores associados ao uso de psicofármacos em um abrigo para idosos no Brasil.

TIPO DE ESTUDO E LOCAL: Estudo retrospectivo observacional realizado no Abrigo da Velhice de Rio Claro, Instituto de Biociências, Universidade Estadual Paulista.

MÉTODOS: Dados sobre prescrições foram extraídos dos prontuários médicos dos 108 idosos moradores do abrigo. Sessenta e cinco sujeitos (idade média \pm desvio padrão $=74,5 \pm 9,4$ anos), em uso regula de medicação, constituíram a amostra. Foram examinados os efeitos das variáveis sociodemográficas e clínicas sobre o padrão de prescrição de psicofármacos.

RESULTADOS: As mulheres recebiam mais psicofármacos ( $p=0.038)$; indivíduos em uso de medicações para doenças cardiovasculares recebiam menos psicofármacos $(p=0.001)$. Houve correlação negativa entre número de psicofármacos prescritos e, ambos, idade $(p=0.009)$ e número de medicações clínicas $(p=0.009)$.

CONCLUSÃO: Embora preliminares, os resultados indicam as doenças cardiovasculares como a variável clínica que mais influenciou a prescrição de psicofármacos. Uma excessiva precaução por parte dos clínicos pode explicar parcialmente este resultado. Novas investigações, com amostras maiores e de diferentes regiões são desejáveis para confirmação destes dados.

PALAVRAS-CHAVE: Envelhecimento. Asilos para idosos. Prescrição de medicamentos. Cardiopatias. Psicofarmacologia. 